\title{
UNLOCKING BLADDER CANCER
}

The diagnostics, treatment and five-year survival rates for bladder cancer are largely unchanged since the 1990s. Research into cancer genomics, risk factors and immune therapies could hold the key to progress against this malignant disease. By Chris Berdik; infographic by Mohamed Ashour.

\section{LAYERS OF RISK}

Most cases of bladder cancer occur in the cells of the bladder's innermost lining, the urothelium. In most patients, the cancer has not spread far. These 'non-muscle-invasive' tumours are easier to treat and much less lethal than tumours that have grown into the muscle wall or beyond.

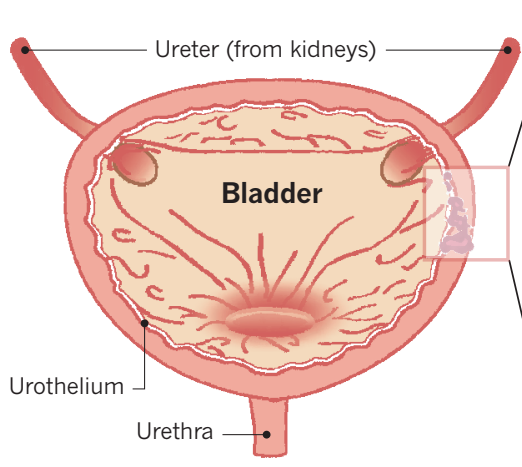

\section{BLADDER-CANCER DIAGNOSES}

Most cases of bladder cancer are the urothelial type. The less-common types are: squamous cell carcinoma, adenocarcinoma, small-cell carcinoma, and sarcoma.
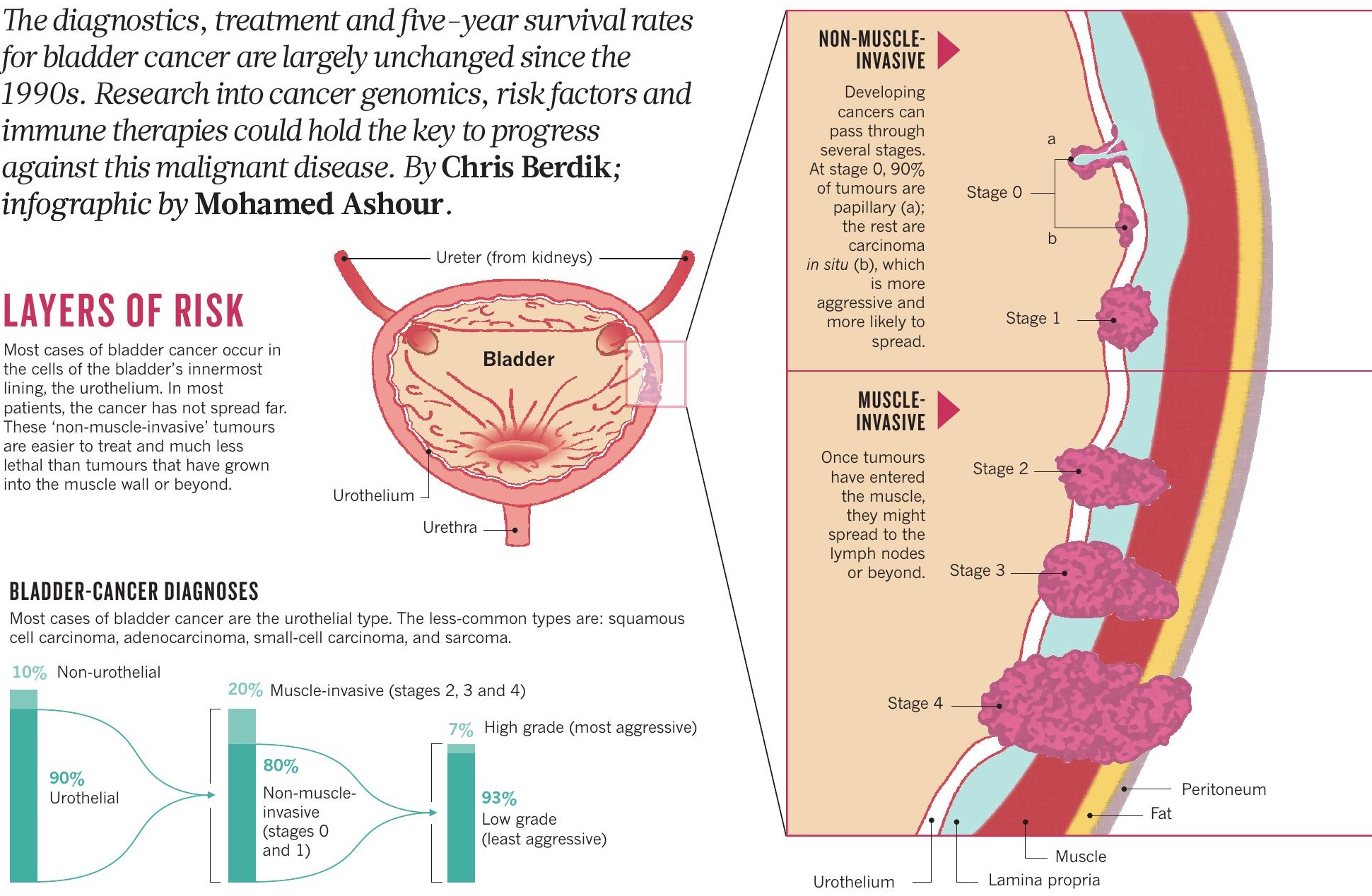

\section{NO COMFORT FOR OLD MEN}

Men are about three to four times more likely than women to get bladder cancer, but women are typically diagnosed with more-advanced cancer and have a worse

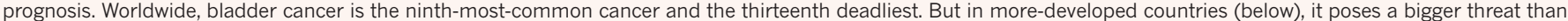
many other cancers because fewer new treatment and prevention options have been developed.

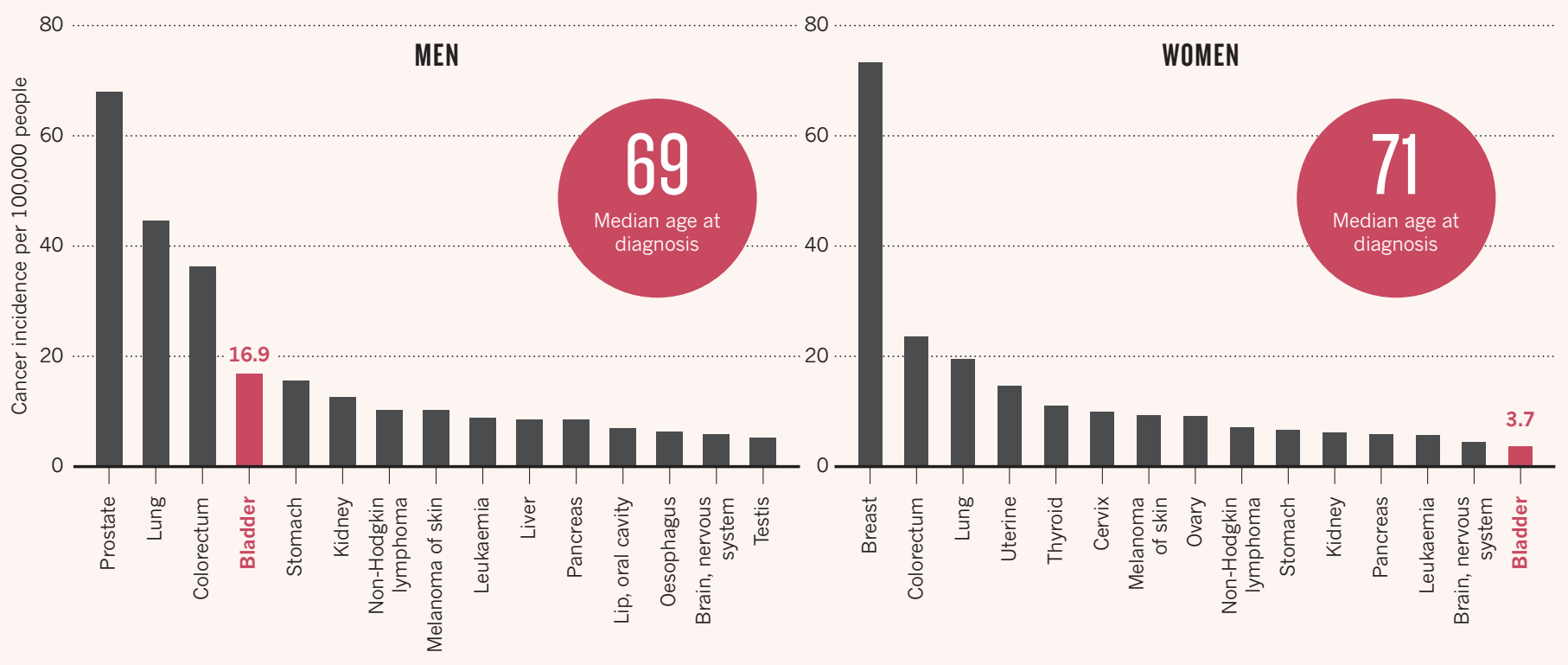


FIVE-YEAR SURVIVAL RATES

If caught early, long-term survival is good.

STAGE 0

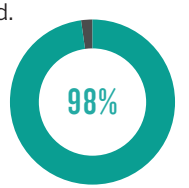

STAGE 1

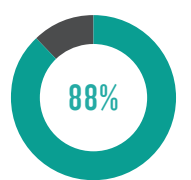

\section{TREATMENTS}

Doctors typically use a combination of different therapies to treat bladder cancer, depending on the size, grade and number of tumours.

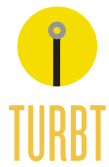

Transurethral resection of bladder tumour (TURBT). Non-muscle-invasive tumours are removed by a cystoscope topped with a cauterizing wire loop.

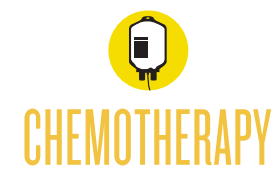

Can be given before or after surgery, either directly

to the bladder or systemically if the cancer is invasive.

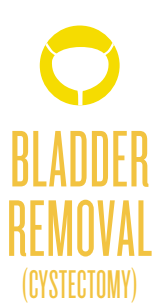

The bladder is replaced with either a 'neobladder' made from a piece of intestine, or diversion to an external urostomy bag.

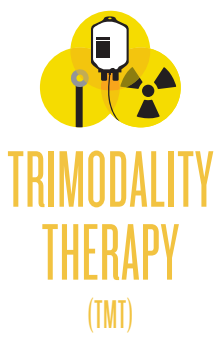

This combines deep TURBT with chemotherapy and radiation. Five-year survival rates are comparable to

cystectomy, but up to $30 \%$ of TMT patients still need to

have their bladders removed.

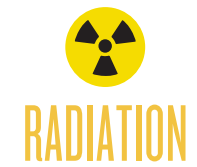

A high-energy beam is focused on the cancer from outside the body, often in combination with chemotherapy.

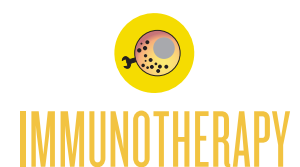

The bacillus Calmette-Guérin (BCG) vaccine, which was originally used to prevent tuberculosis, is made with bacteria that trigger an immune response.

\section{SURVIVAL AND RECURRENCE}

\section{SURVIVAL UNCHANGED}

Unlike many other cancers, there has been
no improvement in survival rates for bladder no improvement in surviv
cancer for three decades.

$$
\begin{array}{ll}
\text { - Prostate } & \text { - Kidney } \\
\text { - Breast } & - \text { Colorectal } \\
\text { - Bladder } & - \text { Lung }
\end{array}
$$

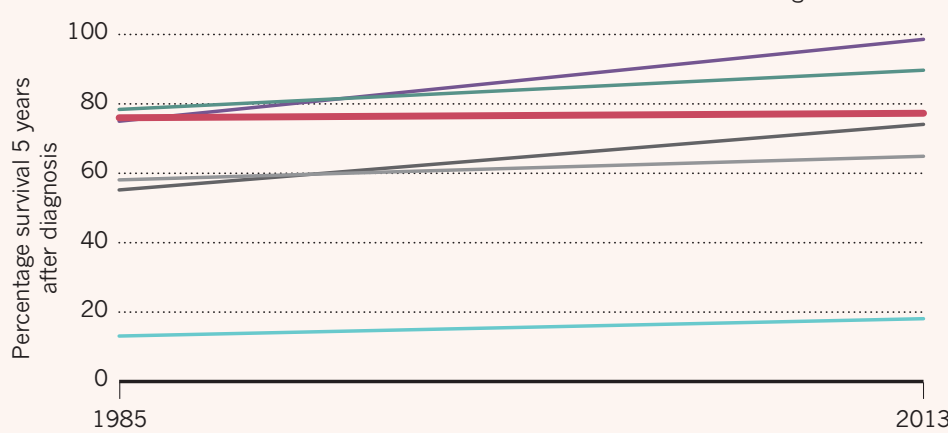

\section{RECURRENCE}

After surgery, people with bladder cancer should have regular cystoscopies (typically every three months for the first year or two, and then every six months) to see if the cancer returns, as well as imaging and urine tests.

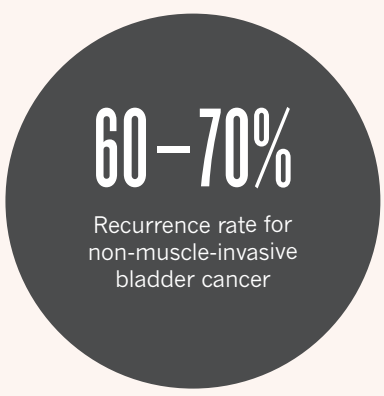

\section{A TOXIC LEGACY}

Smoking is linked with up to $65 \%$ of bladder-cancer cases in men and about $30 \%$ in women.

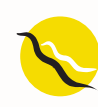

Bladder infections from a parasitic water-borne flatworm called Schistosoma can lead to bladder cancer (see page S46).
Exposure to aromatic amines, used to process paint rubber, dyes and petroleum products, is a risk factor.

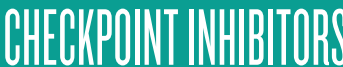 \\ Five newly approved drugs called checkpoint inhibitors \\ block the signals given by \\ cancer cells to evade the \\ \$36). Currently approved only \\ for stage 3 and stage 4 bladder \\ cancer, they are being tested \\ against less-advanced cancers.}

